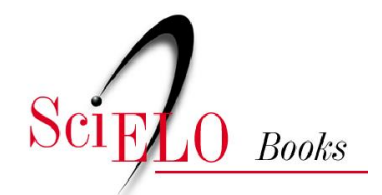

\title{
Sobre a civilização do renascimento
}

\author{
Sérgio Cardoso
}

\section{SciELO Books / SciELO Livros / SciELO Libros}

CARDOSO, S. Sobre a civilização do renascimento. In: PINTO, F.M., and BENEVENUTO, F., comps. Filosofia, política e cosmologia: ensaios sobre o renascimento [online]. São Bernardo do Campo, SP: Editora UFABC, 2017, pp. 15-32. ISBN: 978-85-68576-93-9. https://doi.org/10.7476/9788568576939.0003.

\section{@ $(0$}

All the contents of this work, except where otherwise noted, is licensed under a Creative Commons Attribution 4.0 International license.

Todo o conteúdo deste trabalho, exceto quando houver ressalva, é publicado sob a licença Creative Commons Atribição $\underline{4.0}$.

Todo el contenido de esta obra, excepto donde se indique lo contrario, está bajo licencia de la licencia $\underline{\text { Creative }}$ Commons Reconocimento 4.0. 
Possui graduação em Filosofia pela Pontifícia Universidade Católica de Campinas (1969), Licenciatura pela Faculdade de Filosofia Nossa Senhora Medianeira (1971), mestrado em Filosofia pela École des Hautes Études em Sciences Sociales (1979) e doutorado em Filosofia pela Universidade de São Paulo (1990). Atualmente é professor doutor da Universidade de São Paulo. Tem experiência na área de Filosofia, com ênfase em Ética e Filosofia Política, pesquisando principalmente sobre os seguintes temas: Ética e Política em Montaigne, filosofia política no Renascimento e tradição republicana. Em 2014 organizou a obra Retorno ao republicanismo (UFMG) e é autor de diversos capítulos, sendo o mais recente o artigo "A matriz romana", publicado no livro Matrizes do Republicanismo (UFMG), em 2013. 


\section{SOBRE A CIVILIZAÇÃO DO RENASCIMENTO ${ }^{1}$}

Sérgio Cardoso

Comecemos pela palavra civilização. Tomo esta palavra em seus sentidos usuais, pois o campo de significação a que nos remete é bem conhecido. Mas não creio que seja ocioso recordar-lhe a etimologia. Devemos lembrar que a palavra tem origem nas expressões latinas 'civitas', cidade; civis, cidadão; e civilis (o adjetivo), o que é próprio do cidadão, do participante da vida da cidade. Deste primeiro sentido, a palavra passa a designar também, mais extensamente, a boa convivência na cidade e, depois, afabilidade, cortesia, polidez.

Penso também em uma outra conotação semântica. Talvez tenha havido contaminação de uma palavra com sonoridade próxima: o verbo ciere: cieo (no presente), civi (no pretérito),

\footnotetext{
1 Este texto corresponde à conferência de abertura do SIMPOFI, Simpósio de Política e Filosofia, realizado em 2014 na UFF/Campos. O evento reuniu pesquisadores que buscam compreender a riqueza e a complexidade que envolve o tema da cultura do Renascimento em algumas das suas diversas faces: política, filosófica, retórica, histórica ou literária.
} 
citum (no particípio), que significa mover, por em movimento, abalar, agitar. Assim, o civil e a civilização passariam a apontar também a vida agitada das cidades, da convivência intensa e permanente dos homens, por oposição à vida calma, quieta do campo (do rus), do mundo rural. Vida rústica, rude e mesmo 'ruída' (por aproximação do verbo ruere: ruir, desabar por peso), bruta (pesada), de um homem grosseiro, pesado de espírito (e frequentemente de corpo, como pensavam os gregos, esculpidos pela ginástica, dos bárbaros).

Em todo caso, civilidade e civilização nos remetem à agitação da convivência dos cidadãos, polidos uns pelos outros pela fricção da vida em comum. E a elas se opõe a rusticidade, grosseria dos homens brutos, não cultivados, não polidos, afastados dos benefícios da vida civil. Daí a ideia de civilização como o conjunto das aquisições da vida em sociedade (costumes, técnicas, conhecimentos, valores), enquanto tais aquisições possibilitam uma convivência social polida e afável, urbana e humana. A civilização refere-se ainda às aquisições, às criações dos homens, obtidas mediante cultivo, esforço, trabalho e reflexão, sendo assim, dignas de serem preservadas - o que a associa à ideia de tradição. Mas ela assinala também, por fim, um ideal de elevação espiritual, de busca do refinamento dos modos de vida e da convivência social, que aponta para o futuro, para a ideia de aperfeiçoamento e progresso desta civilização.

Ora, esta ideia potencialmente universalista de uma humanidade em processo de formação e civilização, beneficiária das criações humanas do passado e portadora de um ideal de elevação espiritual e moral a realizar-se indefinidamente no tempo, surge de maneira expressa e consciente - reivindicada com marca de um novo tempo - justamente no Renascimento, na civilização do Renascimento iniciada no final do século 
XIV na Itália. E é preciso lembrar que a própria ideia de uma História da Civilização ou da Cultura surge no final do século XIX a partir do estudo de Jacob Burckhardt sobre este período do Renascimento italiano.

As grandes civilizações anteriores nunca se pensaram nestes termos universalistas de uma formação do Homem ou da produção da própria humanidade. A polarização grego/ bárbaro, romano/bárbaro, cristão/pagão ou infiel, pensa-se sempre em vista da extensão para outros homens (ou imposição aos outros homens) do universo de uma cultura verdadeira, legítima, constituída por valores, leis, crenças, modos de vida já bem estabelecidos e legitimados. As grandes civilizações anteriores pensaram-se sempre numa perspectiva 'imperial', espacialmente imperial, nunca no sentido temporal de um processo de criação e educação da humanidade, como ocorre no Renascimento. Pois, é no Renascimento que se impõe a concepção do Homem como um ser em constituição, in fieri, como um animal capaz de produzir-se, plasmar a si próprio. Um animal, como assinala Pico della Mirandola, cuja forma, cujo ser, deriva da sua ação, de sua própria atividade. O único animal que é o que faz de si mesmo; animal divino, porque criador de seu Mundo e de si próprio. E podemos observar que esse mote relativo ao Homem como "plasmador e artífice de si mesmo"- em função do poder de sua livre vontade - será repetido em formulações diversas por todo o Renascimento. Erasmo, por exemplo, dirá: "homines non nascuntur, sed fingitur". As árvores, os animais, nascem tais; já os homens não nascem, eles se fazem, plasmam-se como homens.

Não há paralelo na História de uma civilização como esta, difundida em um sentido quase que exclusivamente 
cultural e, num certo sentido supranacional, não imperial. Talvez, deste paradigma só se aproxime aquela que foi certamente a primeira grande civilização mundial (o que equivalia, então, ao nosso 'global'), aquela que o Renascimento quer justamente fazer renascer, a civilização do Helenismo dos séculos I a III a.C., uma civilização à qual somos tão pouco atentos e que, embora seja ela o berço e a matriz da nossa cultura do Ocidente, estudamos tão pouco.

Refiro-me àquela cultura de origem grega que, em um certo sentido, civilizou os romanos e em que a história da República Romana está enraizada; pois, é preciso lembrar que os romanos tornam-se os Romanos que conhecemos depois da Guerras Púnicas, quando se deixaram helenizar pela cultura herdeira da Grécia Clássica, a da civilização da Koiné, a civilização comum que se constituiu sob a égide da língua grega depois da decadência das póleis, a partir do 'império universal' de Alexandre - mais precisamente, a partir do esfacelamento do Império universal de Alexandre.

Sabemos que, dois anos após sua morte, o domínio macedônio, que alcançava do Mediterrâneo à Índia, da Itália ao Egito e o norte da África, se esfacela em três grandes blocos: Macedônia e Grécia, o Egito e, com sede na Síria, a Ásia. Mas, se se esfacelam o poder e a força; firma-se e se expande, no entanto, a hegemonia de cultura grega: o uso comum da língua grega (o grego da Koiné); um estilo de vida à maneira grega (organização das cidades, artes, filosofia); enorme atividade comercial e uma vida cosmopolita influenciada por homens cultos de origem grega (médicos, artistas, filólogos, filósofos). Estas grandes transformações sociais e culturais se exprimiram e encontraram apoio nas chamadas 'escolas filosóficas do helenismo' - um momento da história do pensamento em 
que as filosofias buscam, sobretudo, uma orientação prática; pensam-se como 'artes de viver', acessíveis a todos; entendem buscar, em meio às imensas mudanças políticas, sociais, culturais e religiosas, os caminhos de uma vida feliz. É esta cultura 'mundial' que os romanos 'herdam', elaboram e transformam; é ela que, pela mediação da Renascença - renascimento da romanidade educada pela Paideia grega, como assinala Heidegger - chega até nós, constituindo os fundamentos da civilização moderna.

Não vou aqui entrar no terreno das investigações sobre a gênese histórica da civilização do Renascimento. Trata-se de um assunto que a corporação dos historiadores tem investigado amplamente. Desde Jacob Burckhardt, passando por Hans Baron e tantos outros, como, hoje, Quentin Skinner ou, entre nós, nosso amigo Newton Bignotto. Basta lembrar que há no início desta história, já a partir do século XII, a situação anômala das comunas independentes do norte da Itália (do velho Regnum Italicum que nunca se firmou), vassalas de direito do Sacro Império e submetidas às prerrogativas do Papado, mas de fato independentes em função dos conflitos entre o imperador e a Igreja, incapazes ambos de exercerem um poder efetivo. Há os desgastes internos da Religião Católica, a corrupção do clero, as alianças políticas, que terminam no grande cisma do final do século XIV, os dois Papas, o Pontificado transferido para Avignon, e tantos episódios mais. Há, na perspectiva cultural, o desgaste da Escolática e o surgimento de uma nova cultura cívica que exalta a vida ativa em detrimento da contemplativa. E há, não se pode desconsiderar Burckhardt, a busca da grandeza perdida da Itália e o desejo do renascimento da república Romana. Mas deixemos esta história de lado, esta questão do surgimento deste novo 
tempo do Humanismo, para tentar apreciar seu próprio projeto formador, civilizador.

Comecemos por lembrar que o Humanismo tira sua denominação de um gênero específico de formação - que assinala o núcleo de seus interesses - os 'studia humanitatis'. Tecnicamente falando, humanista era o sujeito que ensinava ou estudava um conjunto de disciplinas designado 'humanidades' (os tais 'studia humanitatis'). Esta expressão fora usada anteriormente por Cícero e Aullus Gellus, e depois retomada no Trecento, para indicar o estudo das antigas 'Artes Liberais', os conhecimentos do homem livre, a súmula dos conhecimentos e artes chamadas racionais, por oposição às artes mecânicas ou servis (aplicadas à matéria sensível) e às artes mistas, como a arquitetura. E quais são esses conhecimentos do homem livre, as artes racionais? São os conhecimentos organizados, já no período helenístico, no Trivium - Gramática, Retórica e Dialética - e no Quadrivium - Aritmética, Geometria, Astronomia e Música, a formação fundamental que avança pelo Medievo. Em meados do Século XV, estas sete matérias haviam se rearticulado em um outro conjunto de disciplinas, agora justamente chamadas 'studia humanitatis’: Gramática (bom uso da língua), Retórica (arte oratória, a palavra eficaz, ajustada às circunstâncias), História (associada à oratória política, os 'exempla'), Poesia (inspeção dos sentimentos, exploração da vida afetiva), Filosofia Moral (a formação moral, os costumes).

Humanistas são, pois, aqueles que fazem profissão de praticar estas cinco disciplinas, que hoje, grosso modo, poderíamos chamar literárias, sobretudo tendo em vista seu vínculo estreitíssimo com as Letras da Antiguidade Clássica. Profissionalmente, se sabe, estes humanistas serão docentes 
de suas disciplinas em escolas e universidades ou educadores privados; serão secretários de Príncipes e de Comunas (para os quais escreverão cartas, discursos, obras históricas), Diplomatas, Chanceleres e homens engajados em todos os ofícios que exigem a prática do falar bem e escrever bem - saberes de grande utilidade e prestígio, que se derrama na formação de pregadores, médicos, aristocratas e políticos. Estes humanistas herdam, como mostrou Paul Kristeller, grande parte das artes do Dictatores medievais, a Ars Dictaminis (a arte da composição de cartas e documentos) e a Ars Arengandi (arte dos discursos públicos, adequados a diferentes ocasiões), já que tomam seu saber das Letras clássicas como eminentemente dirigido para um exercício prático.

Mas o que se ensina e como se ensina na formação e na pedagogia destes 'studia humanitatis'? Como se pensa o ciclo de estudos da formação humanista? Por volta de meados do século XVI, quando tais estudos já são amplamente hegemônicos e estão bem estabelecidos, podemos identificar - sobretudo na França que, então, os cultiva com entusiasmo - um ciclo de estudos que teve vida longa. Vejamos! Depois dos estudos elementares (aprender a ler e escrever e a aritmética básica, os nobres com seus preceptores privados, os poucos outros em escolas paroquiais), que se abrevia o mais possível, vêm os 'studia humanitatis': gramática (3 anos), poesia (2anos), retórica (1 ano) - os 'studi inferiora', dos colégios jesuítas. Seguem depois 2 ou 3 anos de filosofia (frequentemente filosofia aristotélica), os 'studia superiora' dos jesuítas, para se chegar em seguida às faculdades da tradição: Artes, Medicina, Direito, Teologia. Observem, pois, que entre os estudos elementares e aqueles especializados nas faculdades, temos 
um ciclo médio de 8 ou 9 anos de estudos, inteiramente dedicado às humanidades. Tentemos, porém, nos aproximar mais do desenvolvimento efetivo destes estudos. Tomemos o caso de um dos maiores e mais importantes colégios humanistas da França, o Collège de Guyenne de Bordeaux, onde estudaram Michel de Montaigne, entre 1539 e 1547-48, e muitos outros personagens importantes.

Fundado em 1533 e dirigido desde então até 1547 pelo português André de Gouveia, um adepto da moderna pedagogia erasmiana e próximo da orientação dos 'humanistas evangelistas', então suspeitos de heresia, trata-se, pois, de um Colégio bastante avançado no espírito do tempo, sendo que muitos de seus professores têm simpatias pela Reforma, como o irlandês Georges Buchanan, que foi professor de Montaigne, cuja presença no colégio, como a de Gouveia, nos permite verificar ainda o ambiente internacional em que se desenvolvia, então, a formação humanista. Devemos observar também que o empenho principal da atividade deste colégio é o ensino do Latim: "Latino sermoni cognoscendo haec schola in primo dedicata est". O latim é visto como o veículo e o medium da cultura da eloquência, e a eloquência como o medium da sabedoria em todos os assuntos humanos.

Trata-se de aprender bem latim (o bom latim e não mais aquele corrompido da cultura eclesiástica da Idade Média). Temos aqui o centro do projeto pedagógico e cultural do Renascimento. Porque pensam o latim como o veículo do saber: ele é o meio que permite o contato com a experiência paradigmática dos Antigos. Seu ensino, portanto, não é pensado como o ensino de uma língua morta. Os textos antigos - pelos quais os humanistas se apaixonam - não são apenas modelos de expressão verbal; são fontes de ensinamentos e 
sabedoria. Por isso, diz Eugenio Garin, “o retorno aos clássicos não é (como frequentemente se pensa) o retorno à pureza da língua [...]. Não é uma questão de bem escrever, mas de bem pensar". Os autores antigos são lidos por suas qualidades humanas, por ser possível servir-se de suas criações e de sua experiência para nossa própria orientação de vida. Trata-se de recuperar através de seus escritos o que se criou e se fez de mais excelente no passado da humanidade, visto que é por espelhar-se em tal experiência (imitatio) que cada homem pode atingir sua própria excelência, a virtude. A ideia é a da exemplaridade cultural e moral dos grandes homens do passado; de onde o empenho em ressuscitá-los através de seus escritos, de conversar com eles (Petrarca escreve cartas para Cícero), de compreendê-los para melhor se compreender. A leitura dos clássicos permite distanciar-se de si mesmo, da própria particularidade e pequenez, para alçar-se ao nível da humanidade nas suas configurações mais excelentes.

Mas o latim não é apenas o veículo do contato com o passado da humanidade, ele é também, como língua internacional, o veículo do contato com os homens cultos do presente. Não é (como o inglês hoje) veículo de comércio, de imposições econômicas e culturais; não é instrumental. Ele é como espaço de realização e comunicação do humano, como médium do humano - uma língua sagrada. De um lado, o lugar do distanciamento de si mesmo, da particularidade das línguas vernaculares. De outro lado, o espaço da projeção de um ideal de sabedoria universal, do processamento da experiência humana; o lugar simbólico da sabedoria dos homens (e não da sabedoria divina, veiculada pela teologia).

Os humanistas detestam o latim bárbaro da Igreja e da escolástica medieval; não só porque é associado à teologia, 
mas justamente porque para elas é uma língua instrumental e, assim, maltratada e permeada de artifícios. Os medievais são vistos como bárbaros também porque corrompem a língua, a mutilam, impedindo o acesso à grande cultura dos homens; tratam os antigos como instrumentos para seus próprios fins (como fizeram com Platão e, sobretudo, com Aristóteles). Compreende-se, pois, a obsessão humanista não só em descobrir os textos dos clássicos, mas em penetrar seu sentido e realidade autêntica, viva, com suas feições particulares, com o sentido que tiveram para os próprios autores. Para dialogar com Platão, para tornar-se seu discípulo é preciso reencontrar o verdadeiro, o autêntico Platão; reencontrá-lo na sua autenticidade. Não se buscam mais as 'autoritates' medievais, mas os 'autênticos'; não mais as ideias do texto, mas o texto exato, a tradução literal, o comentário filológico e histórico, para restituí-los em seu sentido original e dar-nos acesso, como que vivo e direto, aos seus autores.

Podemos, portanto, compreender que o princípio fundamental da pedagogia humanista seja o aprendizado do latim pelo contato direto com os textos dos clássicos, e que a função do mestre era apenas a de proporcionar e facilitar esse contato. Ler os próprios autores em textos autênticos; frequentar os autores, ter familiaridade com eles. Ler, reler, comentar, imitar, para a aquisição das próprias habilidades e a formação do próprio espírito. "Não se trata de repetir uma verdade já expressa”, diz Garin, "mas de observar como se constitui esta verdade [...] a ação do modelo não é a de produzir uma cópia, mas de suscitar uma obra nova”. E, para tal é preciso estudar as obras mais marcantes de cada ramo do saber. Quer ser um bom orador? Leia e imite Cícero. Um bom poeta? Imite Virgílio. Um bom geômetra? Leia Euclides. E daí por diante. 
É verdade que esta imitação acabará por ser o problema maior desta cultura, quando ela perder seu espírito de criação e se tornar servil, pura erudição e pedantismo. Montaigne já a ironizará: "Cícero diz isto; eis o estilo (modos) de Platão; estas são as palavras mesmas de Aristóteles. Mas e nós, o que dizemos nós mesmos? Pois aquilo faz um papagaio. Apenas guardamos as opiniões e saberes dos outros e basta. É preciso fazê-los nossos". Enfim, abaixo a cultura frívola da citação. A pura erudição e a imitação servil assinalarão a perda da cultura humanista.

Mas para compreender a fundo esta formação humanista, talvez seja tão importante quanto saber o que se estuda, saber como se estuda. Não poderei desenvolver aqui esta questão, mas os incentivo a investigá-la. Procurem conhecer a técnica erasmiana de assimilação da literatura antiga, o uso dos 'liber locorum rerum', que os ingleses chamam 'Commonplace books', os cadernos dos 'lugares comuns' das argumentações, a assimilação das opiniões reputadas. E procurem saber como os estudantes usam criativamente seus três cadernos de lugares comuns: o 'liber sermonis', em que anotam palavras e expressões para suas composições e discursos; o 'liber styli', cujas anotações lhes servem de gramática aplicada; o 'liber locorum rerum' que lhes permite inventariar informações gerais, sobretudo morais. Os estudantes são levados a organizar o que leem, armazenando seu aprendizado nestes 'loci', como uma espécie de instrumento artificial de memória posta nestes cadernos destinados a selecionar e classificar de modo metódico as proposições que possam ser usadas nas próprias criações, conversas e escritos.

Não foi tranquila, evidentemente, a aceitação desta relação com os clássicos antigos e destas inovações do ensino 
humanista, como mostra a polêmica momentosa em torno das mudanças que Pierre dela Ramée pretendeu introduzir no Collège Royal, mesmo já em meados do século XVI. Os tradicionalistas dizem que ao introduzir-se estas formas de ensino abrir-se-ão as portas a todo tipo de abuso e que os estudantes, sem parâmetros, ver-se-ão submetidos a todo tipo de perigo moral, além dos riscos para as crenças religiosas e as tentações do ceticismo. É o que diz Pierre Galland, sendo ele, no entanto, um professor do Collège de France, uma instituição concebida para ancorar na França a cultura humanista.

A luta de Erasmo fora justamente a de mostrar que o caminho do humanismo não implica hostilidade ou rejeição à religião cristã. É o que ele argui, contra esse fundamentalismo cristão, na grande diatribe em defesa dos estudos dos clássicos que encontramos no seu Antibarbari, um texto de juventude, escrito por volta de 1480, e estudado entre nós pela nossa Fabrina Magalhães Pinto e por outras teses brasileiras, como a de Sílvio Lúcio Nassaro. A acusação que o humanista rebate é a de que se abandonam os autores cristãos pelos pagãos, cujas obras não são apenas mais difíceis, mas licenciosas e mesmo obscenas: "estão proibindo os jovens de lerem autores castos, para ler os lascivos", esbraveja Pierre Galland. Mas Erasmo o contesta de antemão ao afirmar que encontramos nos clássicos antigos um saber genuíno e que o legado inteiro de nossos conhecimentos vem desta fonte, pois os cristãos acrescentaram bem pouco a esse legado - quando não o danificaram e confundiram. Seu mote central é o de que "tudo que há no mundo pagão de valioso, de brilhantemente dito, engenhosamente pensado, diligentemente transmitido, foi preparado pelo Cristo para sua sociedade (a Igreja)". Como os hebreus tomaram para si os espólios dos egípcios, devemos tomar para 
nós o ouro da sabedoria dos clássicos, a prata de seus discursos - para nosso uso e conhecimento. A sabedoria humana do mundo antigo é o berço do mistério cristão; é "preparatio evangelica”.

O grande humanista Thomas Morus, o amigo de Erasmo, que dá aos seus filhos a formação das letras, diz que "os estudos das letras aperfeiçoam a razão e a tornam fecunda como uma terra lavrada sobre a qual se semeiam os grãos dos bons preceitos": "[...] a piedade para com Deus, a caridade para com o próximo e, para eles mesmos (fala dos filhos), a modéstia e a humildade cristãs". Trata-se de reafirmar a articulação e coesão da cultura e da religião, 'eruditio et pietas'. Mas o que esses homens com lucidez vêm nos lembrar é, como assinala ainda Garin, "a necessidade de salvar a dimensão humana da formação (da escola); de um lado, face aos interesses da religião, de outro lado, face às exigências da formação profissional, técnica, utilitária, instrumental - pregada esta, como diz Gramsci, como democrática, mas que, na verdade, perpetua as diferenças sociais, cristaliza as diferenças da sociedade". Cabe, portanto, a nós, ainda hoje, entender que é o ensino humanista - entre nós visto como elitista - que é democrático, liberador e equalizador. Só ele forma o homem ativo, moral e politicamente autônomo, o cidadão capaz de atuar livremente em companhia dos outros.

Mas há ainda, para nós, um outro grande ensinamento desta civilização renascentista, pois ela nos dá o paradigma de uma cultura que pela primeira vez na História projeta no outro - o pagão, o bárbaro - o lugar da sabedoria e se coloca no lugar do aprendiz, do discípulo. Uma civilização inédita em que nossa cultura cristã mostrou-se capaz - não obstante enormes resistências - de admirar e se mirar nos conhecimentos 
e artes, valores, usos e costumes de um 'outro', o mundo pagão dos antigos. E mais: investiu nele seu paradigma e ideal de sabedoria humana; conferiu-lhe uma exemplaridade capaz de alimentar sua reflexão moral, de produzir em si uma aspiração de elevação na direção da excelência em todos os domínios da atividade dos homens. Não percamos, pois, as lições desta grande cultura e civilização do Renascimento.

\section{Referências}

BARON, Hans. The Crisis of the Early Italian Reinaissance. Princeton: Princeton University Press, 1966.

BIGNOTTO, Newton. Republicanismo e Realismo: um perfil de Francesco Guicciardini. Belo Horizonte: Ed. UFMG, 2006.

BIGNOTTO, Newton. Origens do Republicanismo Moderno. Belo Horizonte: UFMG, 2001.

. (Org.). Pensar a República. Belo Horizonte: Ed. UFMG, 2000.

Nota Metodológica: Gicciardini leitor de Maquiavel. Discurso, São Paulo, n. 29, p. 111-131, 1998c.

Maquiavel Republicano. São Paulo: Loyola, 1991.

BURCKHARDT, Jacob. The civilization of the Renaissance in Italy. New York: The Modern Library, 2002.

GARIN, Eugenio. L'Humanisme Italien: Bibliothèque de l'évolution de l'humanité. Traduit de l'allemand et de l'italien 
par Sabina Crippa et Mario Andrea Limoni. Paris: Albin Michel, 2005.

- Le Zodiaque de la Vie: Polemiques Antiastrologiques a la Renaissance. Traduit de l'italien par Jeannie Carlier. Paris: Les Belles Lettres, 1991.

. Moyen Âge et Renaissance. Traduit de l'italian par Claude Carne. Paris: Gallimard, 1989.

KRISTELLER, Paul Oskar. Renaissance Thought I: the Classic, Scholastic and Humanistic Strains. New York: Harper and Row, 1961.

. Tradição Clássica e Pensamento do Renascimento. Tradução de Artur Morão. Lisboa: Edições 70, 1995.

MIRANDOLA, Pico dela. Discurso sobre a dignidade do Homem [1487]. Trad. Maria de Lourdes Sirgado Ganho. Lisboa: Edições 70, 2008.

MONTAIGNE, M. Les Essais. Éd. Pierre Villey. Paris: PUF, 1999.

MORE, Thomas. L'Utopie. Présentation, texte original, apparat critique, exegèse, traduction et notes de André Prévost. Paris: Mame, 1978.

PINTO, Fabrina Magalhães. O discurso humanista de Erasmo de Rotterdam: uma retórica da interioridade. Tese de doutorado. PUC-Rio, Rio de Janeiro, 2006.

SKINNER, Quentin. As Fundações do Pensamento Político Moderno. Tradução de Renato Janine Ribeiro e Laura Teixeira Motta. São Paulo: Companhia das Letras, 1996. 
. Liberdade antes do Liberalismo. Tradução de Raul Fiker. São Paulo: Ed. UNESP, 1999.

. Maquiavel. Tradução de Maria Lúcia Montes. São Paulo: Brasiliense, 1988.

- Visions of Politics. Renaissance Virtues. Cambridge:

Cambridge University Press, 2002. 